\title{
The antagonist and synergist potential of cholinium-based deep eutectic solvents
}

\author{
Inês P.E. Macário ${ }^{\mathrm{a}}$, Sónia P.M. Ventura ${ }^{\mathrm{b}, *}$, Joana L. Pereira ${ }^{\mathrm{a}}$, Ana M.M. Gonçalves ${ }^{\mathrm{a}, \mathrm{c}}$, \\ João A.P. Coutinho ${ }^{\mathrm{b}}$, Fernando J.M. Gonçalves ${ }^{\mathrm{a}, *}$ \\ a Department of Biology \& CESAM, University of Aveiro, 3810-193 Aveiro, Portugal \\ ${ }^{\mathrm{b}}$ CICECO - Aveiro Institute of Materials \& Department of Chemistry, University of Aveiro, 3810-193 Aveiro, Portugal \\ ${ }^{c}$ MARE - Marine and Environmental Sciences Centre, Department of Life Sciences, Faculty of Sciences and Technology, University of Coimbra, 3004-517 Coimbra, \\ Portugal
}

\section{A R T I C L E I N F O}

\section{Keywords:}

Deep Eutectic Solvents

Cholinium chloride

Hydrogen-Bond Donor and Acceptor

Microtox $^{\circledast}$ test

Toxic units

Synergistic and antagonist effects

\begin{abstract}
A B S T R A C T
The design of environmentally friendlier solvents has gained increasing relevance in the last decade. Deep eutectic solvents (DES) have recently emerged, with advantages like low-cost and putative lower environmental impact. However, information about DES toxicity is still scarce. This work aims to contribute to profiling the ecotoxicity of DES based on cholinium chloride $([\mathrm{Chol}] \mathrm{Cl})$. Six DES were addressed, combining [Chol]Cl (as hydrogen bond acceptor - HBA) with ethylene glycol, glycerol, 1,2-propanediol, propionic acid, 1-propanol, and urea as hydrogen bond donors (HBD), in different molar ratios. The Microtox ${ }^{\circledR}$ Acute Toxicity Test, was used for assessing their toxicity towards the marine bacteria Allivibrio fischeri. Because the dissociation of DES in water is expected, analysis appraising the mixtures toxicity theory should be considered, which is a step forward in this field. This analysis suggested that [Chol] $\mathrm{Cl}$ and all HBD with the exception of propionic acid:[Chol] $\mathrm{Cl} 1: 2$ and 4:1 behave antagonistically, which is contrary to what has been suggested previously. The most extreme cases are Urea:[Chol] $\mathrm{Cl}$ and 1-Propanol:[Chol] $\mathrm{Cl}$, with $\mathrm{EC}_{50}$ values higher than their starting materials dosed singly, configuring very promising and biocompatible alternative solvents. Toxicity was found to be dependent on DES composition, as well as on molar proportions of the starting materials.
\end{abstract}

\section{Introduction}

The concept of "Green Chemistry" was introduced in the early 1990 's with the propose of designing and applying chemical products and processes in order to reduce, or preferentially eliminate, the use and generation of hazardous substances (Anastas and Warner, 1998). In this field, the design of environmentally friendlier solvents compared to their traditional counterparts has gained increased attention.

Deep eutectic solvents (DES) emerged in this context. They are simple to prepare and do not need purification, have low-cost production due to the low cost of starting materials, and have been showing good biocompatibility (Hayyan et al., 2013b; Jhong et al., 2009; Singh et al., 2012). These solvents were first developed combining urea with cholinium chloride (Abbott et al., 2003), but DES can be prepared through the mixing of two or three different components belonging to different chemical families (e.g., quaternary ammonium salts, amides, organic acids, polyalcohols), forming an eutectic mixture based on hydrogen bonding interactions between the components, with a melting point much lower than either of the individual components (Dai et al., 2013; Ruß and König, 2012; Zhang et al., 2012). The melting point depression of DES is hypothesized to be caused by charge delocalization due to the hydrogen bonding between the halide anion (hydrogen bond acceptor; HBA) and the hydrogen bond donor (HBD) (Abbott et al., 2003). However, recent studies using ab initio molecular dynamic simulations were developed to gain insights on the charge spreading in the liquid state and casted strong doubts on this hypothesis (Zahn et al., 2016).

DES can be used in several applications in areas such as synthesis, metal-catalysed organic reactions and biocatalysis, electrochemistry, nanomaterial's, extraction and purification processes and in the pharmaceutical and biomedical fields (Farias et al., 2017; Mbous et al., 2017a; Smith et al., 2014; Tang and Row, 2013; Zhang et al., 2012). However, the application of these solvents at an industrial scale requires the previous knowledge of their environmental impact and fate (e.g. biodegradation and ecotoxicity) (Radošević et al., 2015). Studies about DES toxicity are still scarce to fully understand their toxicological

\footnotetext{
* Corresponding author.

E-mail addresses: spventura@ua.pt (S.P.M. Ventura), fjmg@ua.pt (F.J.M. Gonçalves).
} 
profile, and the overall assumption of the DES benign character is mostly based on the low toxicity of their precursors (Radošević et al., 2015). However, this assumption disregards putative interaction effects between the DES compounds, including synergic toxic effects (Hayyan et al., 2013b). The toxicity of cholinium chloride and phosphoniumbased DES was assessed through organisms, namely crustaceans (Hayyan et al., 2013a, 2013b), bacteria (De Morais et al., 2015; Hayyan et al., 2013a, 2013b; Zhao et al., 2015; Wen et al., 2015), fungi (Cardellini et al., 2015; Juneidi et al., 2016), plants (Radošević et al., 2015; Wen et al., 2015), invertebrates (Huang et al., 2014; Wen et al., 2015), fish (Juneidi et al., 2016), mice (Hayyan et al., 2015), and several cell lines (Hayyan et al., 2016, 2015; Mbous et al., 2017b; Paiva et al., 2014). The ecotoxicological profile of the DES previously studied did not highlight any specific rule, being the toxic effects dependent on DES composition, concentration, and test model. This hampers the application of predictive models of DES ecotoxicity, thus requiring its specific characterization, before generally concluding on their benign character and their suitability for large-scale use.

The aim of this study is to evaluate the ecotoxicity of cholinium chloride-based DES, since this is one of the widespread precursors most used in their formation. Cholinium chloride or (2-hydroxyethyl)trimethylammonium chloride) abbreviated in this work as [Chol] $\mathrm{Cl}$, is a quaternary ammonium salt member of vitamin B family and used in several metabolic pathways (Florindo et al., 2014). It is cheap, biodegradable and non-toxic, and it is approved as a nutritional additive for animals (FEEDAP, 2011). Six [Chol]Cl-based DES containing ethylene glycol, glycerol, 1,2-propanediol, propionic acid, 1-propanol, and urea as HBD, in different molar ratios, were screened for their environmental hazardous potential using the Microtox Acute Toxicity Test. This sensitive and widely accepted test (Johnson, 2005) allowed us to gain specific insights on the role of the HBD and molar ratio between HBA and HBD in the overall toxicity of [Chol]Cl-based DES. Considering the dissociating nature of DES when standing in a significant amount of water (Dai et al., 2015; Passos et al., 2016), this work provides a basic analysis of their toxicity considering them as binary mixtures of two precursors. In this context, the toxicity of different DES analyzed as mixtures was compared to that of their precursors.

\section{Material and methods}

\subsection{DES preparation}

The following chemical compounds were used for DES preparation: [Chol]Cl (98\% purity) was purchased from Acros Organic ${ }^{\circ}$ Geel, Belgium; ethylene glycol (99.5\% purity) was purchased from Sigma Aldrich $^{\circ}$, St. Louis, Missouri, EUA; 1,2-propanediol from Panreac ${ }^{\circ}$, Barcelona, Spain; propionic acid (99\% purity) from Merck ${ }^{\circledR}$, Darmstadt, Germany; glycerol $(99,8 \%$ purity) was purchased from Fischer Chemical $^{\circ}$, Hampton, New Hampshire, EUA; urea (99\% purity) from Panreac ${ }^{\circ}$, Barcelona, Spain; and 1-propanol (99.5\% purity) was acquired from Merck ${ }^{\circ}$, Darmstadt, Germany.

Each DES was prepared in the following molar ratios: 1:2, 1:1, 2:1 and 4:1 (HBD:HBA). Briefly, HBD and HBA were added gravimetrically to closed vials and heated with constant agitation. After the formation of a transparent liquid, the mixture was cooled down to room temperature to obtain each DES. Since the purpose of this study was the evaluation of the ecotoxicological character of DES, some of the stock eutectic mixtures were prepared by adding a known volume of water. The water content of the starting materials and of DES was determined by Karl Fischer titration and considered in the calculation of the toxicity (Table S1).

\subsection{Microtox Acute Toxicity Test}

The Microtox ${ }^{\oplus}$ Toxicity Test (Microbics Corporation, 1992) was used to assess the toxicity of the prepared DES as well as the starting materials, through the inhibition of the luminescence of the marine bacteria Allivibrio fischeri. This test was performed using a range of diluted aqueous solutions (from $0 \%$ to $81.9 \%$ ) of each stock solution. After 5, 15, and $30 \mathrm{~min}$ of exposure to the test dilutions, the light output of the luminescent bacteria was measured and compared with the light output of a blank control sample. In this work, the concentrations of each sample tested were not checked before the toxicity measurements. The reasoning for this option combines three essential features of the established test system. First, the exposure period is very short (30 min), which renders very unlikely any significant degradation; degradation of these compounds under the conditions of this specific assay was not evidenced so far. Then, under these conditions, [Chol] Cl and each HBD used in this work are completely soluble in water (Farias et al., 2018; Vieira et al., 2018), which renders the final solutions stable. Finally, the focus here was in the methodologies used for the analysis of DES toxicity rather than on establishing actual effect concentrations, although we estimate them for internal comparison purposes. These data were used to estimate the concentrations that promote $50 \%, 20 \%$ and $10 \%$ of luminescence inhibition (Effective Concentration, $\mathrm{EC}_{50}, \mathrm{EC}_{20}$ and $\mathrm{EC}_{10}$, respectively) and the corresponding $95 \%$ confidence intervals through a non-linear regression, using the least-squares method to fit the data to the logistic equation. These analyses were performed using STATISTICA, version 8.0 software (StatSoft, 2007). This test was applied to DES and starting materials described above.

\subsection{Mixture toxicity assessment}

In order to compare DES toxicity with the toxicity of corresponding starting materials, we assumed that each DES is a mixture composed by the two starting materials as all concentrations tested in the Microtox ${ }^{\circledast}$ assay comprise more than $18.3 \%$ of water (note that only in the highest concentration tested (81.9\%) the amount of water is less than 50\%) (see Table S1). A basic approach to primarily address mixtures toxicity is the application of the model of Concentration Addition (CA) for the joint action of chemicals (Berenbaum, 1985). CA assumes that mixture components act as dilutions of each other because they have a similar mode of action. DES are thought to act as membrane disruptors (Hayyan et al., 2015; Mbous et al., 2017b), thus we are assuming here that this is the common mechanism through which they exert toxic effects. The suitability of the CA model is also supported by its argued higher conservativeness in environmental assessment compared to the alternative model for mixture toxicity of Independent Action that assumes dissimilar modes of action of the mixture components (Cedergreen et al., 2008). CA is mathematically represented in Eq. (1), where $\mathrm{C} i$ represents the individual concentrations of each $i$ component present in the mixture with a total effect of $\mathrm{x} \%$ and ECxi are those concentrations of the components that would alone cause the same effect $x i$ as observed for the mixture.

$\sum_{i=1}^{n} \frac{C i}{E C x_{i}}=1$

As deducible from CA formulation, the toxic strength of a mixture is given by the sum of the quotients $\mathrm{Ci} / \mathrm{ECx}_{\mathrm{i}}$ (toxic units; $\mathrm{TU}$ ), which should equal 1 if there are no interactions between the components of the mixture, i.e. if they behave through simple additivity. On this basis, we calculated the TU sum for each DES $\left(\mathrm{TU}_{\mathrm{DES}}\right)$ using the estimated $\mathrm{EC}_{50}$ following exposure to each DES and the corresponding starting materials, as detailed in Eq. (2):

$T U_{D E S}=\left(\frac{E C_{50} A D E S}{E C_{50} A}\right)+\left(\frac{E C_{50} B D E S}{E C_{50} B}\right)$

where, A and B represent each component of the mixture, i.e. the starting materials; $\mathrm{EC}_{50}$ DES correspond to the $\mathrm{EC}_{50}$ values of the starting materials (A or B) dosed as part of the DES (this concentration 
values where calculated according to their molar proportion in the $\mathrm{DES}$ ); $\mathrm{EC}_{50}\left(\mathrm{~A}\right.$ or $\mathrm{B}$ ) corresponds to the $\mathrm{EC}_{50}$ values of the starting materials. If the outcome ( $\mathrm{TU}_{\mathrm{DES}}$ ) equals 1 , the logical interpretation is that there are no interactions between the components of the mixture and each starting material acts as a dilution of the other when exerting the monitored effect. A $\mathrm{TU}_{\mathrm{DES}}$ higher than 1 suggests an antagonist behavior of the mixture components, reflecting an environmentally protective effect of the DES compared to the corresponding starting materials dosed alone. On the contrary, $\mathrm{TU}_{\mathrm{DES}}$ below 1 suggests synergic interactions between the starting materials within DES in inducing toxicity to $A$. fischeri.

\section{Results and discussion}

This study evaluates the toxic profile of six [Chol]Cl-based DES, as well as their starting materials, using the CA model of mixtures toxicity. For this purpose, a comparative analysis of estimated 30 min-EC $\mathrm{E}_{50}$ regarding the luminescence of $A$. fischeri was carried out, both considering the starting materials and series combining them in different proportions to establish different DES. Given their relevance as environmental benchmarks for future integrated risk assessment, $\mathrm{EC}_{10}$, $\mathrm{EC}_{20}, \mathrm{EC}_{50}$, were estimated and are presented in Supplementary Material (Table S2).

\subsection{Ecotoxicity of the starting materials}

Concerning starting materials, glycerol showed the highest 30 min$\mathrm{EC}_{50}$ value $\left(114,194.5 \mathrm{mg} \mathrm{L}^{-1}\right)$ followed by ethylene glycol $\left(96,491.62 \mathrm{mg} \mathrm{L}^{-1}\right)$ and 1,2-propanediol $\left(82,573.93 \mathrm{mg} \mathrm{L}^{-1}\right)$, with $95 \%$ confidence intervals overlapping, thus suggesting that their toxicity towards the bacteria was not significantly distinct (Table 1). On the other hand, propionic acid was found to be the most toxic starting material $\left(30\right.$ min- $\left.\mathrm{EC}_{50}=4.857 \mathrm{mg} \mathrm{L}^{-1}\right)$, followed by [Chol] Cl showing a 30 min- $\mathrm{EC}_{50}$ value higher by two orders of magnitude (Table 1). Although [Chol] $\mathrm{Cl}$ is perceived as a non-toxic molecule (FEEDAP, 2011) and clearly biocompatible - provided that mammalian cells use it as the preferred cellular raw material for the synthesis of cellular membrane lipids (Lodish et al., 2000) - our results show that their environmental impact should be determined as [Chol] $\mathrm{Cl}$ is combined with different HBD to form different DES. Based on the United Nations Globally Harmonized System of Classification and Labelling Chemicals (GHS) (UN, 2011), only propionic acid can be considered hazardous to the environment $\left(1<\mathrm{EC}_{50}<10 \mathrm{mg} \mathrm{L}^{-1}\right)$.

The octanol-water partition coefficients ( $\log \mathrm{P})$ could be a valuable parameter to gain an insight on the putative mechanism ruling the toxicity of starting materials. This parameter can be used to explain structure-(eco)toxicity relationships across chemical series due to the ability of 1-octanol to mimic the behavior of a lipid phase (Sangster, 1997). A higher affinity to 1-octanol would translate a high lipophilic character, and consequent higher toxicity, due to the affinity of the chemicals to living tissues (Sangster, 1997).
Although there is no information regarding the values of $\log \mathrm{P}$ of the studied DES, information about the hydrophilicity/lipophilicity of the starting materials is available and assist interpretations on DES behavior as interacting with a biological membrane.

All HBD starting materials have low $\log \mathrm{P}$ values, suggesting their hydrophilicity: glycerol (-2.32); urea (-2.11); ethylene glycol (-1.69); 1,2-propanediol (-1.34); 1-propanol $(0.34)$ and propionic acid $(0.25)$ (Chemspider, accessed on January 23, 2018). As a narcotic mode of toxic action can be assumed ruled by the interaction with cell membranes, hydrophilic molecules are normally less toxic because they can more hardly reach the inner cell than lipophilic alternatives (Verhaar et al., 2000, 1992). In fact, propionic acid was the least hydrophilic compound and that showing the higher toxicity to A. fischeri compared to other HBD (Table 1). The increase of hydrophilicity is in good agreement with the decrease of toxicity, confirming that membrane permeability to the HBD should be the main driver of the noticed toxic effects. The higher affinity to water (lower $\log \mathrm{K}_{\mathrm{ow}}$ ) resulting in lower toxicity was also described for other molecular compounds (McKarns et al., 1997). Since these log P values were lower than 4.5, one can assume that the affinity of these compounds to lipids is insufficient to exceed the bio-accumulation criterion (ECHA, 2017).

\subsection{Ecotoxicity of cholinium-based DES}

Recurrently in the literature, DES toxicity has been analyzed assuming these mixtures as novel non-dissociating compounds, instead of recognizing them as actual binary mixtures of two precursors. However, in the last years several works studied the integrity of the DES complex in water and find that water levels above a certain threshold, cause the dissociation of the two starting materials (Dai et al., 2015; Hammond et al., 2017; Passos et al., 2016; Zhekenov et al., 2018). Supported by this information we proposed to apply the mixture theory to studied DES toxicity. Still, comparative analyses of bulk DES toxicity (EC $_{50}$ values) are useful as a first step to generally understand the environmental hazard level variation provided by changes in DES composition, and they allow (limited) comparison with previous toxicity studies.

In this context, it is worth highlighting that, regardless HBD:HBA ratios, some tested DES mixtures (ethylene glycol:[Chol]Cl, glycerol: [Chol]Cl, propionic acid:[Chol] $\mathrm{Cl}$ and 1,2 propanediol:[Chol]Cl; Fig. 1) induced $50 \%$ A. fischeri luminescence inhibition at mass-per-volume concentrations between the benchmark found for corresponding HBA and HBD, consistently with e.g. De Morais et al. (2015). On the contrary, the $\mathrm{EC}_{50}$ values found for urea:[Chol] $\mathrm{Cl}$ and 1-propanol:[Chol] $\mathrm{Cl}$ were higher than those found for both the respective starting materials as also found in previous studies with cell lines (Hayyan et al., 2015). Furthermore, the general trend for a decrease in the $\mathrm{EC}_{50}$ values as the HBD changes (considering that the HBA was kept unchanged as [Chol]Cl) and as its molar proportion increases within each DES can be interpreted in Fig. 1. This suggests that the HBD may have a role in modulating the ecotoxicity of the DES and in fact, several studies have been arguing that HBD have a significant influence on the toxicity

Table 1

Effective concentration values $\left(\mathrm{EC}_{10}, \mathrm{EC}_{20}, \mathrm{EC}_{50}\right)$ in $\mathrm{mg} \mathrm{L}^{-1}$ and the respective $95 \%$ confidence intervals $(\mathrm{CI})$, obtained after 30 min of exposure of the marine bacteria A. fischeri (Microtox toxicity test) to different chemical compounds used as starting materials to produce DES. Bold font type was used to highlight the lowest (the most toxic) and highest (the least toxic) values.

\begin{tabular}{|c|c|c|c|}
\hline Chemical compound & $\begin{array}{l}\mathrm{EC}_{10}\left(\mathrm{mg} \mathrm{L}^{-1}\right) \\
(95 \% \mathrm{CI})\end{array}$ & $\begin{array}{l}\mathrm{EC}_{20}\left(\mathrm{mg} \mathrm{L}^{-1}\right) \\
(95 \% \mathrm{CI})\end{array}$ & $\begin{array}{l}\mathrm{EC}_{50}\left(\mathrm{mg} \mathrm{L}^{-1}\right) \\
(95 \% \mathrm{CI})\end{array}$ \\
\hline [Chol] Cl & $240.9(138.0-343.7)$ & $291.4(206.5-376.3)$ & $403.3(347.7-458.9)$ \\
\hline Ethylene glycol & $23,997.5(8524.0-39,471.0)$ & $40,118.6(20,927.6-59,309.5)$ & $96,491.6(69,956.5-123,026.7)$ \\
\hline Glycerol & $18,780.9(1077.7-36,484.2)$ & $36,585.9(10,844.9-62,326.8)$ & $114,194.5(69,121.6-159,267.4)$ \\
\hline Propionic acid & $3.1(2.4-3.8)$ & $3.6(3.1-4.2)$ & $4.8(4.6-5.0)$ \\
\hline 1,2-Propanediol & $33,192.8(17,547.7-48,837.9)$ & $46,475.9(30,401.4-62,550.3)$ & $82,573.9(66,258.3-98,889.6)$ \\
\hline Urea & $8234.5(5073.3-11,395.8)$ & $12,344.5(8880.1-15,809.0)$ & $24,643.2(20,553.7-28,732.8)$ \\
\hline 1- Propanol & $3065.0(1922.6-4307.4)$ & $4572.3(3199.1-5945.4)$ & $9052.3(7474.7-10,629.9)$ \\
\hline
\end{tabular}




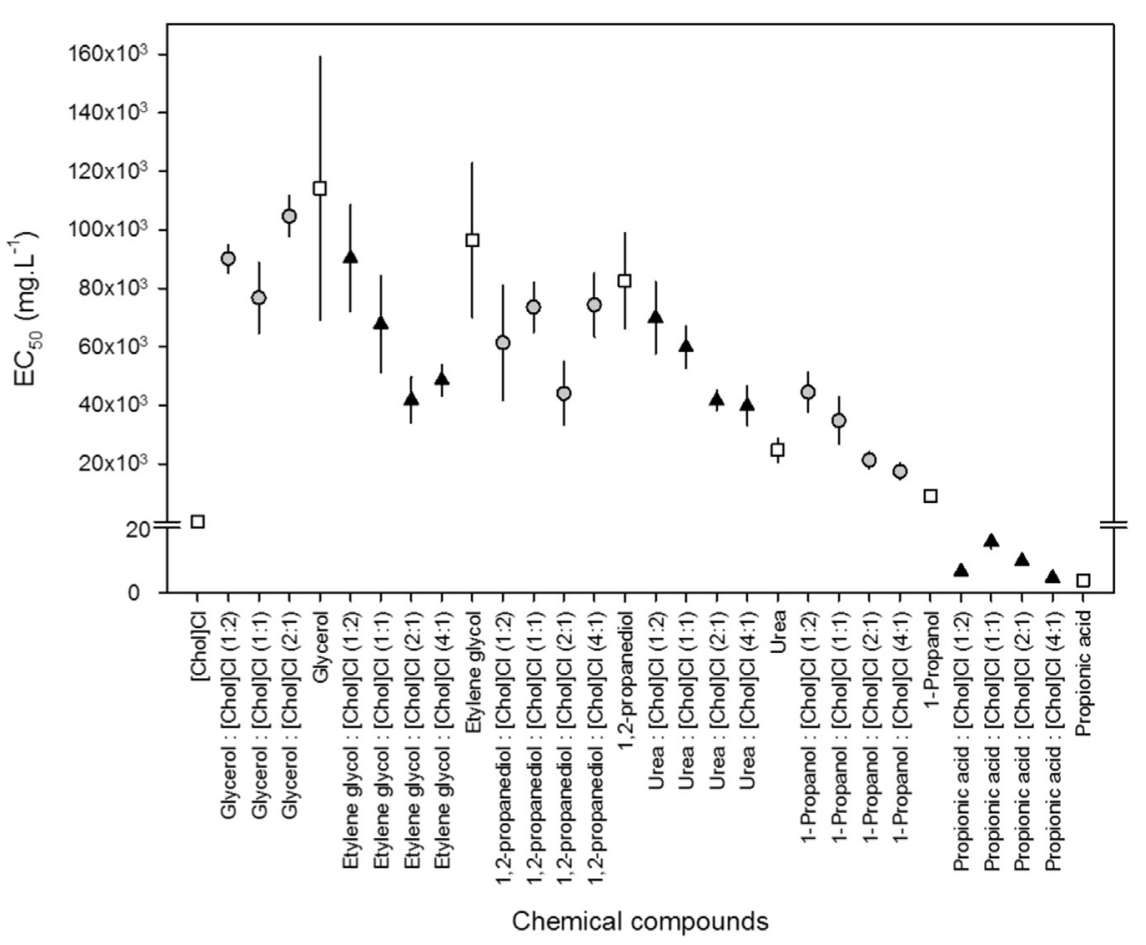

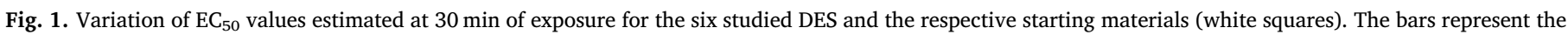
confidence limits.

\section{Table 2}

Toxic strength corresponding to the 30 min- $\mathrm{EC}_{50}$ values determined following exposure of $A$. fischeri to each DES. The type of interaction between the components of each mixture (HBD and HBA) suggested by the TU values was noted in addition to facilitate interpretation.

\begin{tabular}{lll}
\hline DES (molar ratio HBD:HBA) & TU sum & Interaction \\
\hline Ethylene glycol: [Chol] Cl (1:2) & 183 & Antagonist \\
Ethylene glycol: [Chol] Cl (1:1) & 117 & Antagonist \\
Ethylene glycol: [Chol] Cl (2:1) & 55 & Antagonist \\
Ethylene glycol: [Chol] Cl (4:1) & 44 & Antagonist \\
Glycerol: [Chol] Cl (1:2) & 168 & Antagonist \\
Glycerol: [Chol] Cl (1:1) & 115 & Antagonist \\
Glycerol: [Chol] Cl (2:1) & 112 & Antagonist \\
Propionic acid: [Chol] Cl (1:2) & 0.4 & Synergist \\
Propionic acid: [Chol] Cl (1:1) & 1.4 & Antagonist \\
Propionic acid: [Chol] Cl (2:1) & 1.3 & Antagonist \\
Propionic acid: [Chol] Cl (4:1) & 0.8 & Synergist \\
1,2-Propanediol: [Chol] Cl (1:2) & 120 & Antagonist \\
1,2-Propanediol: [Chol] Cl (1:1) & 118 & Antagonist \\
1,2-Propanediol: [Chol] Cl (2:1) & 52 & Antagonist \\
1,2-Propanediol: [Chol] Cl (4:1) & 58 & Antagonist \\
Urea: [Chol] Cl (1:2) & 143 & Antagonist \\
Urea: [Chol] Cl (1:1) & 104 & Antagonist \\
Urea: [Chol] Cl (2:1) & 56 & Antagonist \\
Urea: [Chol] Cl (4:1) & 37 & Antagonist \\
1-Propanol: [Chol] Cl (1:2) & 92 & Antagonist \\
1-Propanol: [Chol] Cl (1:1) & 61 & Antagonist \\
1-Propanol: [Chol] Cl (2:1) & 29 & Antagonist \\
1-Propanol: [Chol] Cl (4:1) & 17 & Antagonist \\
\hline
\end{tabular}

profiles (De Morais et al., 2015; Hayyan et al., 2016, 2013b, 2013a; Paiva et al., 2014; Radošević et al., 2015; Wen et al., 2015). Although some authors refer to synergism between the starting materials of phosphonium (Hayyan et al., 2013a) and [Chol]Cl-based DES (Hayyan et al., 2015), many still support the viewpoint that a DES complex remains integrated in aqueous solution (Hayyan et al., 2015, 2013a; Huang et al., 2014; Juneidi et al., 2016), which is challengeable under the conditions used to expose biological systems to DES.

As shown by e.g. De Morais et al. (2015), different molar proportions between the HBD and HBA in a DES imply a variation of toxicity and different physico-chemical properties, which seems to suggest that each molar ratio represents an individual compound that should be studied as such. Still, there are evidences denoting that when DES are diluted in aqueous solutions (such as in dilutions set for and within the Microtox ${ }^{\circledast}$ Test), water competes for the hydrogen bonding and the DES tends to become a mixture of the starting materials dissociated in water. Recently, Dai et al. (2015) showed a progressive rupture of hydrogen bonding network of NADES upon addition of water and established that following an addition of water of more than $50 \%$ $\mathrm{v} / \mathrm{v}$, the resulting solution consisted of a mixture between the starting materials. Furthermore, Passos et al. (2016) concluded on DES integrity destruction when used in the formation of aqueous biphasic systems, with some very specific exceptions (Farias et al., 2017). They argued, that in general and when in water, the disruption of the hydrogen-bond interactions of the (DES) complex occurs, as a result of the isolated components preferential solvation by water.

Despite these evidences, and as to our knowledge, the present study is the first that attempts to apply the principles of mixtures toxicity theory, in order to more accurately understand the differences in toxicity as different molar ratios between starting materials are used to synthesize DES. If one assumes that the DES is a mixture combining two starting materials diluted in water for testing (note that only the highest concentration tested is less diluted than $50 \%$ in the Microtox ${ }^{\circledR}$ protocol we used), DES toxicity can only be directly compared with that of the starting materials when the toxicity of one and the other component are exactly the same, which is unlikely to happen and did not happen in the present study. An alternative approach that takes into account the relative toxicity of the mixture components is the use of the dimensionless TU scale for comparison as we carried out here.

The toxic strength of the DES, expressed as the TU for the various molar ratios between the starting materials studied is shown in Table 2. This calculation of TU allows the interpretation of the interaction between DES components while inducing toxic effects and indicates the potential of each mixture to behave synergistically or antagonistically. For most tested systems, the TU was much higher than 1, suggesting a strong antagonist interaction between the starting materials. This 
behavior supports previous reports of DES as having lower toxicity than their individual components (Huang et al., 2014; Juneidi et al., 2016; Radošević et al., 2015; Wen et al., 2015), denoting a potential environmentally protective effect of the DES compared to the corresponding starting materials dosed alone. A tendency towards more than additive, possibly synergistic effects was only noticed for some molar ratios of DES composed by propionic acid as HBD (TU values below 1 in Table 2). Synergistic effects are translated in practice by a higher toxicity of the DES, hence higher environmental hazard potential, compared to its starting materials dosed alone. It is noteworthy that this TU-based analysis is consistent with the picture provided by the previous analysis based on the variation of $\mathrm{EC}_{50}$ values denoting the relevance of the HBD in modulating the DES toxic response. In fact, the antagonism must have been driven by the HBD considering that [Chol]Cl was always the HBA and provided that propionic acid was able to reverse the putative behavior of mixture components from antagonistic to a synergistic one depending on the molar ratios involved. Interestingly, the magnitude of the interaction between the starting materials was invariably higher (higher or lower TU values) as the molar proportion of the HBD was lower within the same DES (1:2 ratio). This suggests that a very small concentration of HBD is sufficient to trigger interactive effects, which generally meant rendering the DES eco-friendlier compared to DES containing higher relative proportions of HBD.

Despite the TU-based analysis provided roughly the same outcome regarding the importance of the HBD in defining the ecotoxicity of the DES compared to the $\mathrm{EC}_{50}$-based analysis, this consistency was not verified regarding general ecotoxicity trends. More specifically, a direct comparison of the $\mathrm{EC}_{50}$ values (see Fig. 1 for an integrative view) indicates that DES require intermediate mass-per-volume concentrations compared to the corresponding starting materials to decrease bioluminescence by $50 \%$. However, their toxicity is not intermediate between starting materials, but rather lower than that of the starting materials dosed singly for all DES, except those using propionic acid as HBD, as evidenced by the strong antagonistic behavior trend denoted by TU analysis (Table 2). These TU values much higher than 1 mean, in practice and by decomposing the CA model formulation, that higher concentrations of mixture components are necessary to jointly elicit $50 \%$ luminescence inhibition than if each component was dosed alone.

Still, a literature review on the toxicity of traditional organic solvents towards $A$. fischeri (Table 3 ) allows questioning on the typical touting of DES as their benign replacers. Our results showed that the most toxic DES (propionic acid:[Chol]Cl), as well as many other tested DES, was more toxic than some of the most used traditional organic solvents (please confront Tables 1, 3). Consistently, the study of Radošević et al. (2015) indicated that other [Chol]Cl-based DES were as good cell line growth inhibitors than some commonly used organic solvents.

The biodegradability of the studied DES plays a highly important role in environmental assessment, complementing the information

Table 3

Literature collection of $\mathrm{EC}_{50}$ values estimated following $30 \mathrm{~min}$ (unless noted otherwise) of exposure of $A$. fischeri to different traditional organic solvents.

\begin{tabular}{lll}
\hline Organic solvent & $\mathbf{E C}_{\mathbf{5 0}}\left(\mathbf{m g ~ L}^{-\mathbf{1}}\right)$ & References \\
\hline Dimethyl sulfoxide & 99,000 & (Suter II and Lewis, 1989) \\
Ethanol & 45,000 & (Suter II and Lewis, 1989) \\
Isopropanol & 42,000 (after 5 min) & (Branson and Dickson, 1991) \\
Acetone & 22,000 & (Suter II and Lewis, 1989) \\
Dimethylformamide & 18,700 & (Suter II and Lewis, 1989) \\
Ethyl acetate & 5822 & (Palabrica and Kaiser, 1991) \\
Dichlorometane & 2532 & (Palabrica and Kaiser, 1991) \\
Chloroform & 1199 & (Palabrica and Kaiser, 1991) \\
Benzene & 108 & (Palabrica and Kaiser, 1991) \\
Phenol & 33 & (Suter II and Lewis, 1989) \\
Toluene & 23.54 & (Grigson et al., 2006) \\
\hline
\end{tabular}

about their ecotoxicological impact and constituting an also very relevant variable defining the green character of newly developed designer chemicals. Recently, Radosévik et al. (2015) and Wen et al. (2015), studying [Chol]Cl-based DES, also showed that they could be considered as "readily biodegradable", being the high levels of biodegradability of the tested DES attributed to the starting materials. In fact, [Chol]Cl is known as readily biodegradable (OECD 301D, 1992), which further supports our expectations that the DES studied in the present study are also biodegradable. Still, this is an important avenue which is worth exploring in the future for a full characterization of the environmental friendliness of [Chol]Cl-based DES.

\section{Conclusions}

This study contributes with important information about the still poorly defined DES ecotoxicity profile by testing [Chol]Cl-based DES with different HBD against the bacteria A. fischeri. The dataset allowed the calculation of $\mathrm{EC}_{50}$ values and such traditional, straightforward analysis suggested no specific rules for DES toxicity. However, it became clear that DES toxicity analysis should not be conducted solely on the basis of mass-per-volume ecotoxicity benchmarks. As the mixtures toxicity theory was used to interpret the results, consistent trends could be depicted. A clear antagonist effect was found between the HBD and the HBA within all tested DES regardless molar ratios involved, except for propionic acid:[Chol] Cl, where a synergic interaction between HBD and HBA was noticed depending on the molar ratio involved. The toxicity of the DES understood as a mixture was dependent on its composition, namely on the $\mathrm{HBD}$ joined to [Chol] $\mathrm{Cl}$, as well as on the molar proportions of the starting materials. The documented antagonism essentially means that DES can be less toxic, thus likely ecofriendlier than either of their starting materials dosed separately (please note that $[\mathrm{Chol}] \mathrm{Cl}$ is a solvent as well). However, their use as alternatives to traditional organic solvents is still not as advantageous as it could be expected from an environmental precautionary point of view, since some DES were found to be comparatively more toxic to the bacteria. Future research avenues should consider organisms representing different functional levels, so that comprehensive knowledge can be collected on how these eutectic mixtures may affect the aquatic ecosystem, this being essential for the setting-up of protective regulatory benchmarks. Also, gathering data on bioaccumulation and biodegradability is an essential step to acquire a better, more accurate view on the environmental sustainability, thus on the benign character of these novel solvent solutions.

\section{Acknowledgments}

Thanks are due for the financial support to CESAM (ref. FCT UID/ AMB// 50017/2013) by FCT - Portuguese Foundation for Science and Technology/MCTES - Ministry of Science (MEC), Portugal, with the cofunding by the FEDER, Europe, within the PT2020 Partnership Agreement and Compete 2020. This work was developed within the scope of the project CICECO-Aveiro Institute of Materials, POCI01-0145-FEDER-007679 (FCT Ref. UID/CTM/50011/2013), financed by national funds through the FCT/MEC and when appropriate co-financed by FEDER under the PT2020 Partnership Agreement. The authors also thank FCT for the project PTDC/ATP-EAM/5331/2014, the doctoral grant of IPE Macário (SFRH/BD/123850/2016) and postdoctoral grants of AMM Gonçalves and JL Pereira (SFRH/BPD/97210/ 2013, SFRH/BPD/101971/2014), respectively. SPM Ventura acknowledges FCT for the contract IF/00402/2015 under the Investigador FCT 2015 program.

\section{Appendix A. Supporting information}

Supplementary data associated with this article can be found in the online version at doi:10.1016/j.ecoenv.2018.09.027. 


\section{References}

Abbott, A.P., Capper, G., Davies, D.L., Rasheed, R.K., Tambyrajah, V., 2003. Novel solvent properties of choline chloride/urea mixtures. Chem. Commun. 99, 70-71. https:// doi.org/10.1039/b210714g.

Anastas, P.T., Warner, J.C., 1998. Green Chemistry: Theory and Practice. Oxford University Press, New York.

Berenbaum, M.C., 1985. The expected effect of a combination of agents: the general solution. J. Theor. Biol. 114, 413-431.

Branson, D.R., Dickson, K.L. (Eds.), 1991. Aquatic Toxicology and Hazard Assessment, Procedings. ASTM International, Philadelphia.

Cardellini, F., Germani, R., Cardinali, G., Corte, L., Roscini, L., Spretic, N., Tieccoab, M., 2015. Room temperature deep eutectic solvents of (1S)-(+)-10-camphorsulfonic acid and sulfobetaines: hydrogen bond-based mixtures with low ionicity and structuredependent toxicity. RSC Adv. 40, 31772-31786.

Cedergreen, N., Christensen, A.M., Kamper, A., Kudsk, P., Mathiassen, S.K., Streibig, J.C., Sørensen, H., 2008. A review of independent action compared to concentration addition as reference models for mixtures of compounds with different molecular target sites. Environ. Toxicol. Chem. 27, 1621-1632. https://doi.org/10.1897/07-474.1.

Dai, Y., van Spronsen, J., Witkamp, G.J., Verpoorte, R., Choi, Y.H., 2013. Natural deep eutectic solvents as new potential media for green technology. Anal. Chim. Acta 766, 61-68. https://doi.org/10.1016/j.aca.2012.12.019.

Dai, Y., Witkamp, G.J., Verpoorte, R., Choi, Y.H., 2015. Tailoring properties of natural deep eutectic solvents with water to facilitate their applications. Food Chem. 187, 14-19. https://doi.org/10.1016/j.foodchem.2015.03.123.

De Morais, P., Gonçalves, F., Coutinho, J.A.P., Ventura, S.P.M., 2015. Ecotoxicity of cholinium-based deep eutectic solvents. ACS Sustain. Chem. Eng. 3, 3398-3404. https://doi.org/10.1021/acssuschemeng.5b01124.

ECHA, 2017. Chapter R.11: PBT/vPvB assessment, In: Guidance on Information Requirements and Chemical Safety Assessment. EuropeanChemicals Agency, pp. 66-68. 〈https://doi.org/10.2823/128621〉.

Farias, F.O., Passos, H., Lima, Á.S., Mafra, M.R., Coutinho, J.A.P., 2017. Is it possible to create ternary-like aqueous biphasic systems with deep eutectic solvents? ACS Sustain. Chem. Eng. 5, 9402-9411. https://doi.org/10.1021/acssuschemeng. $7 \mathrm{~b} 02514$.

Farias, F.O., Passos, H., Sanglard, M.G., Igarashi-Mafra, L., Coutinho, J.A.P., Mafra, M.R., 2018. Designer solvent ability of alcohols in aqueous biphasic systems composed of deep eutectic solvents and potassium phosphate. Sep. Purif. Technol. 300, 84-93. https://doi.org/10.1016/j.seppur.2018.02.029.

FEEDAP, 2011. Scientific Opinion on safety and efficacy of choline chloride as a feed additive for all animal species.

Florindo, C., Oliveira, F.S., Rebelo, L.P.N., Fernandes, A.M., Marrucho, I.M., 2014. Insights into the synthesis and properties of deep eutectic solvents based on choline chloride and carboxylic acids. ACS Sustain. Chem. Eng. 2, 2416-2425. https://doi. org $/ 10.1021 / \mathrm{sc500439w.}$

Grigson, S., Cheong, C., Way, E., 2006. Studies of produced water toxicity using luminescent marine bacteria. In: Kungolos, A.G., Brebbia, C.A., Samaras, C.P., Popov, V. (Eds.), WIT Transactions on Biomedicine and Health, Environmental Toxicology 10. WIT Press, pp. 111-121. https://doi.org/10.2495/ETOX060111.

Hammond, O.S., Bowron, D.T., Edler, K.J., 2017. The effect of water upon deep eutectic solvent nanostructure: an unusual transition from ionic mixture to aqueous solution. Angew. Chem. - Int. Ed. 56, 9782-9785. https://doi.org/10.1002/anie.201702486.

Hayyan, M., Hashim, M.A., Al-Saadi, M.A., Hayyan, A., AlNashef, I.M., Mirghani, M.E.S., 2013a. Assessment of cytotoxicity and toxicity for phosphonium-based deep eutectic solvents. Chemosphere 93, 455-459. https://doi.org/10.1016/j.chemosphere.2013. 05.013.

Hayyan, M., Hashim, M.A., Hayyan, A., Al-Saadi, M.A., AlNashef, I.M., Mirghani, M.E.S., Saheed, O.K., 2013b. Are deep eutectic solvents benign or toxic? Chemosphere 90 , 2193-2195. https://doi.org/10.1016/j.chemosphere.2012.11.004.

Hayyan, M., Looi, C.Y., Hayyan, A., Wong, W.F., Hashim, M.A., 2015. In Vitro and in Vivo toxicity profiling of ammonium-based deep eutectic solvents. PLoS One 10, 1-18. https://doi.org/10.1371/journal.pone.0117934.

Hayyan, M., Mbous, Y.P., Looi, C.Y., Wong, W.F., Hayyan, A., Salleh, Z., Mohd-Ali, O., 2016. Natural deep eutectic solvents: cytotoxic profile. Springerplus 5, 913. https:// doi.org/10.1186/s40064-016-2575-9.

Huang, Z.L., Wu, B.P., Wen, Q., Yang, T.X., Yang, Z., 2014. Deep eutectic solvents can be viable enzyme activators and stabilizers. J. Chem. Technol. Biotechnol. 89, 1975-1981. https://doi.org/10.1002/jctb.4285.

Jhong, H.R., Wong, D.S.H., Wan, C.C., Wang, Y.Y., Wei, T.C., 2009. A novel deep eutectic solvent-based ionic liquid used as electrolyte for dye-sensitized solar cells. Electrochem. Commun. 11, 209-211. https://doi.org/10.1016/j.elecom.2008.11. 001.

Johnson, B., 2005. Microtox ${ }^{\circledast}$ Acute ToxicityTest. In: Blaise, C., Férard, J.-F. (Eds.), SmallScale Freshwater Toxicity Investigations. Springer, Dordrecht, pp. 69-105. https:// doi.org/10.1007/1-4020-3120-3_2.
Juneidi, I., Hayyan, M., Mohd Ali, O., 2016. Toxicity profile of choline chloride-based deep eutectic solvents for fungi and Cyprinus carpio fish. Environ. Sci. Pollut. Res. 23, 7648-7659. https://doi.org/10.1007/s11356-015-6003-4.

Lodish, H., Berk, A., Zipursky, S.L., Matsudaira, P., Baltimore, D., Darnell, J., 2000. Molecular cell biology. New York.

Mbous, Y.P., Hayyan, M., Hayyan, A., Wong, W.F., Hashim, M.A., Looi, C.Y., 2017a. Applications of deep eutectic solvents in biotechnology and bioengineering-Promises and challenges. Biotechnol. Adv. 35, 105-134. https:// doi.org/10.1016/j.biotechadv.2016.11.006.

Mbous, Y.P., Hayyan, M., Wong, W.F., Looi, C.Y., Hashim, M.A., 2017b. Unraveling the cytotoxicity and metabolic pathways of binary natural deep eutectic solvent systems. Sci. Rep. 7, 41257. https://doi.org/10.1038/srep41257.

McKarns, S.C., Hansch, C., Caldwell, W.S., Morgan, W.T., Moore, S.K., Doolittle, D.J., 1997. Correlation between hydrophobicity of short-chain aliphatic alcohols and their ability to alter plasma membrane integrity. Fundam. Appl. Toxicol. 36, 62-70.

OECD 301D, 1992. OECD Guideline for Testing of Chemicals 471 Oecdhttps://doi.org/ 10.1787/9789264071049-en.

Paiva, A., Craveiro, R., Aroso, I., Martins, M., Reis, R.L., Duarte, A.R.C., 2014. Natural deep eutectic solvents - solvents for the 21st century. ACS Sustain. Chem. Eng. 2, 1063-1071.

Palabrica, V.S., Kaiser, K.L.E., 1991. Photobacterium phosphoreum toxicity data index. Water Qual. Res. J. Can. 26, 361.

Passos, H., Tavares, D.J.P., Ferreira, A.M., Freire, M.G., Coutinho, J.A.P., 2016. Are aqueous biphasic systems composed of deep eutectic solvents ternary or quaternary systems? ACS Sustain. Chem. Eng. 4, 2881-2886. https://doi.org/10.1021/ acssuschemeng.6b00485.

Radošević, K., Cvjetko Bubalo, M., Gaurina Srček, V., Grgas, D., Landeka Dragičević, T., Redovniković, R.I., 2015. Evaluation of toxicity and biodegradability of choline chloride based deep eutectic solvents. Ecotoxicol. Environ. Saf. 112, 46-53. https:// doi.org/10.1016/j.ecoenv.2014.09.034.

Ruß, C., König, B., 2012. Low melting mixtures in organic synthesis - an alternative to ionic liquids? Green Chem. 14, 2969-2982. https://doi.org/10.1039/b000000x.

Sangster, J., 1997. Octanol-water Partition Coefficients: Fundamentals and Physical Chemistry. John Wiley \& Sons, Chichester.

Singh, B.S., Lobo, H.R., Shankarling, G.S., 2012. Choline chloride based eutectic solvents: magical catalytic system for carbon - carbon bond formation in the rapid synthesis of $\beta$-hydroxy functionalized derivatives. Catal. Commun. 24, 70-74. https://doi.org/ 10.1016/j.catcom.2012.03.021.

Smith, E.L., Abbott, A.P., Ryder, K.S., 2014. Deep eutectic solvents (DESs) and their applications. Chem. Rev. 114, 11060-11082.

Suter II, G.W., Lewis, M.A. (Eds.), 1989. Aquatic Toxicology and Environmental Fate 11 ASTM International, Philadelphia.

Tang, B., Row, K.H., 2013. Recent developments in deep eutectic solvents in chemical sciences. Mon. Chem. 144, 1427-1454. https://doi.org/10.1007/s00706-0131050-3.

UN, U.N., 2011. Globally harmonized system of classification and labelling of chemicals (GHS), fourth rev. ed, United Nations. New York and Geneva. 〈https://doi.org/10. 1265/jjh.65.5>.

Verhaar, H.J.M., Solbé, J., Speksnijder, J., Van Leeuwen, C.J., Hermens, J.L.M., 2000. Classifying environmental pollutants: part 3. External validation of the classification system. Chemosphere 40, 875-883. https://doi.org/10.1016/S0045-6535(99) 00317-3.

Verhaar, H.J.M., van Leeuwen, C.J., Hramens, J.L., 1992. Classifying environmental pollutants. 1: structure-activity relationships for prediction of aquatic toxicity. Chemosphere 25, 471-491.

Vieira, V., Prieto, M.A., Barros, L., Coutinho, J.A.P., Ferreira, I.C.F.R., Ferreira, O., 2018. Enhanced extraction of phenolic compounds using choline chloride based deep eutectic solvents from Juglans regia L. Ind. Crops Prod. 115, 261-271. https://doi.org/ 10.1016/j.indcrop.2018.02.029.

Wen, Q., Chen, J.X., Tang, Y.L., Wang, J., Yang, Z., 2015. Assessing the toxicity and biodegradability of deep eutectic solvents. Chemosphere 132, 63-69. https://doi. org/10.1016/j.chemosphere.2015.02.061.

Zahn, S., Kirchner, B., Mollenhauer, D., 2016. Charge spreading in deep eutectic solvents. ChemPhysChem 17, 3354-3358. https://doi.org/10.1016/j.toxicon.2008.06.023.

Zhang, Q.H., Vigier, K.D., Royer, S., Jerome, F., 2012. Deep eutectic solvents: syntheses, properties and applications. Chem. Soc. Rev. 41, 7108-7146. https://doi.org/10. 1039/C2cs35178a.

Zhao, B.Y., Xu, P., Yang, F.X., et al., 2015. Biocompatible deep eutectic solvents based on choline chloride: characterization and application to the extraction of rutin from sophora japonica. ACS Sustain. Chem. Eng. 3, 2746-2755. https://doi.org/10.1021/ acssuschemeng.5b00619.

Zhekenov, T., Toksanbayev, N., Kazakbayeva, Z., Shah, D., Mjalli, F.S., 2018. Formation of type III Deep Eutectic Solvents and effect of water on their intermolecular interactions. Fluid Phase Equilib 441, 43-48. https://doi.org/10.1016/j.fluid.2017.01. 022 . 